ARTICLE

Received 26 Oct 2013 | Accepted 19 Dec 2013 | Published 17 Jan $2014 \quad$ DOl: 10.1038/ncomms4154

\title{
Nematode-derived drosomycin-type antifungal peptides provide evidence for plant-to-ecdysozoan horizontal transfer of a disease resistance gene
}

Shunyi Zhu ${ }^{1} \&$ Bin Gao ${ }^{1}$

Drosomycin-type antifungal peptides (DTAFPs) are key innate immunity components of Drosophila and plants and confer resistance to fungal infection. Here we report the discovery of a multigene family of DTAFPs, comprising of 15 members (termed cremycin-1 to crymycin-15), in the fruit nematode Caenorhabditis remanei. Cremycins share highly similar amino-acid sequences and identical precursor organization to drosomycins. Of the 15 cremycin genes, 10 are found to be transcriptionally active and 6 are upregulated after fungal challenge. Synthetic cremycin- 5 is active on filamentous fungi and a series of clinical isolates of human pathogenic yeasts and exhibits low haemolysis and high serum stability. The specific distribution of DTAFPs in a clade of moulting animals (Ecdysozoa), including Arthropoda, Nematoda and Tardigrada, together with the widespread presence in plants but the absence in fungi and protozoans, provides evidence for horizontal transfer of a disease resistance gene between plants and ecdysozoans.

\footnotetext{
${ }^{1}$ Group of Animal Innate Immunity, State Key Laboratory of Integrated Management of Pest Insects and Rodents, Institute of Zoology, Chinese Academy of Sciences, 1 Beichen West Road, Chaoyang District, Beijing 100101, China. Correspondence and requests for materials should be addressed to S.Z. (email: Zhusy@ioz.ac.cn).
} 
D rosophila fruitflies larvae are saprophagous insects of rotting fruits where they compete with some saprobiotic filamentous fungi for the same decaying materials ${ }^{1}$. In a long-term antagonistic interaction with fungi, Drosophila have evolved a set of highly efficient immune system to deal with potential fungal infections ${ }^{2}$, in which drosomycin and six additional paralogs (drosomycin-1 to drosomycin-6) constitute a multigene family of core components fighting against a broad spectrum of filamentous fungi ${ }^{3-5}$. The deletion of drosomycin led to a significantly decreased survival rate of Drosophila melanogaster in the presence of fungi, indicating its role in disease resistance ${ }^{6}$. Drosomycins are synthesized as protein precursors that are then processed into mature peptides of 42-46 residues after removal of a signal peptide. Structurefunction relationship studies have highlighted eight key aminoacid sites involved in the interaction of drosomycin with fungi ${ }^{7}$. These Drosophila peptides belong to the members of a large $\gamma$ thionin (also known as plant defensin) family with structural similarity to invertebrate defensins and scorpion toxins targeting ion channels ${ }^{3,8}$. All these peptides adopt a common cysteinestabilized $\alpha$-helical and $\beta$-sheet $(C S \alpha \beta)$ structure characterized by a well-defined two or three-stranded antiparallel $\beta$-sheet and a short $\alpha$-helix with a similar disulphide bridge pattern?

Whereas in the animal Kingdom only the melanogaster species group of Drosophila (subgenus Sophophora) was found to contain DTAFPs ${ }^{10}$, in the plant Kingdom DTAFPs exist in nearly all the species ${ }^{11}$. In spite of clear homology and extensive research for nearly 20 years $^{3-5}$, the evolutionary history of DTAFPs in plants and Drosophila remains unsolved. On the basis of the prediction that three hypothetical proteins from fungi have similar structure to plant and Drosophila DTAFPs, we tentatively proposed that all these molecules might originate from a common ancestry $^{12,13}$. However, a detailed analysis revealed no detectable sequence similarity between these fungal proteins and DTAFPs ${ }^{12}$. When the fungal sequences were used as queries against the GenBank database with default parameters ${ }^{14}$, no any DTAFPs were returned as hits, and vice versa. These observations provide convincing evidence for their structural analogy other than evolutionary relationship. Alternatively, a patchy distribution (presence or absence patterns) of DTAFPs in plants and Drosophila together with tight association of the fruitflies with plants (i.e., fruits) raises a serious consideration of the possibility of plant-to-Drosophila horizontal gene transfer (HGT, also called lateral gene transfer) ${ }^{15}$.

Here we report the discovery and functional characterization of a multigene family of DTAFPs from the fruit nematode Caenorhabditis remanei ${ }^{16}$, which constitutes clear orthologs of drosomycins. The multigene family encodes protein precursors of $\sim 64$ amino-acids with a signal peptide and mature peptides of 40-42 amino acids in their active form. Synthetic cremysin-5 exhibits therapeutic potential against human pathogenic yeasts. Further phylogenetic distribution analyses indicate that DTAFPs are not only present in Drosophila but are widely distributed to a clade of moulting animals (Ecdysozoa) ${ }^{17}$, including Arthropoda (Insecta, Entognatha, Myriapoda and Arachnida), Nematoda (Rhabditida and Tylenchida) and Tardigrada. These data allow for a more refined analysis of the origin and evolution of this class of disease resistance gene in animals.

\section{Results}

The discovery of new DTAFPs in nematodes. To find whether there exist DTAFPs in non-Drosophila animals, we firstly searched the genomic BLAST databases of the Phylum Arthropoda in GenBank $^{14}$ by TBLASTN using drosomycins and plant defensins as queries. The databases include 63 species classified into four
Classes (Insecta, Crustacea, Myriapoda and Arachnida) with 10 completely sequenced genomes, all derived from Insecta (Supplementary Note 1). Consequently, we found that no species outside of the melanogaster species group of Drosophila contains DTAFPs, consistent with the previous observation ${ }^{10}$. On the basis of the Ecdysozoa hypothesis that nematodes are protostomes closely related to Drosophila and other arthropods ${ }^{17}$, our search scale thus extended to all the nematode genomic databases that include 20 species with two (Caenorhabditis elegans and Caenorhabditis briggsae) completely sequenced. The survey identified two species, the fruit nematode C. remanei and the Northern root-knot nematode Meloidogyne hapla, whose genomes contain genes encoding DTAFPs (Fig. 1).

Nematode DTAFPs are closely related to drosomycins. From the draft genome of C. remanei strain PB4641, we identified a multigene family of DTAFPs comprising 15 members (herein termed cremycin-1 to cremycin-15) (Fig. 2a), in which 13 are tandem located on contig 182 within a region of $\sim 10 \mathrm{~kb}$ and two on contig 219.8 (Fig. 2b). All cremycin genes have a conserved gene structure composed of two exons and one intron of phase-1 that disrupts a positionally conserved amino-acid site located in the N-terminal loop (Fig. 2a; Supplementary Table 1). Cremycins share identical precursor organization with that of drosomycins and most plant defensins ${ }^{3,11}$, which is composed of an $\mathrm{N}$-terminal hydrophobic signal peptide and a C-terminal mature peptide. All the mature peptides contain six conserved cysteines involved in three disulphide bridges. In comparison with most drosomycins and plant defensins, cremycins lack the fourth disulphide bridge, as in the case of several newly discovered orthologs of drosomycins in Drosophila takahashii (Fig. 2a). Cremycin-1 to cremycin-14 display high sequence similarity to each other but they have low similarity to cremycin15 that has a unique amidated C-terminus due to the presence of a Gly-Arg motif ${ }^{18}$ (Fig. 2a).

Sequence similarities among DTAFPs from C. remanei, Drosophila and plants are statistically highly significant with

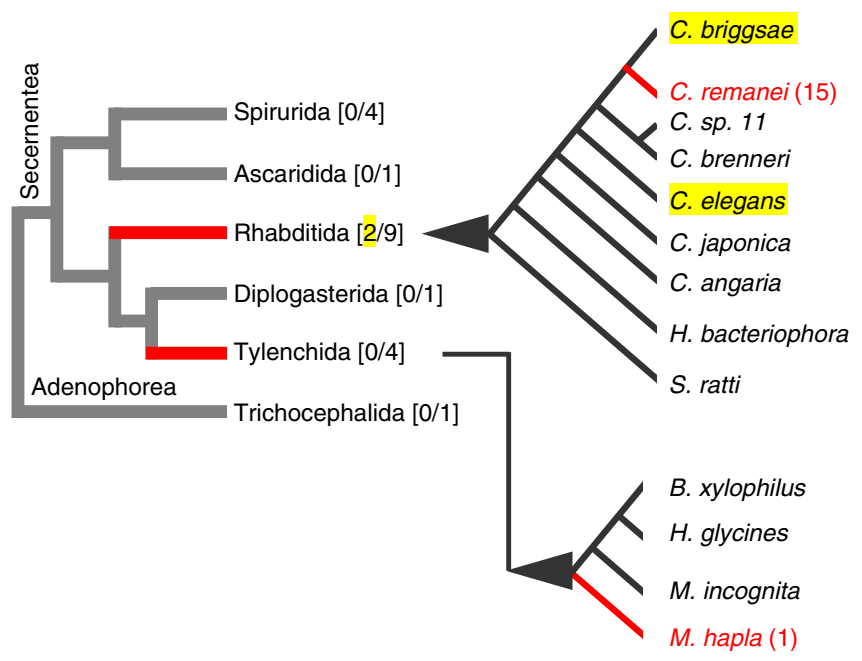

Figure 1 | Genomic BLAST searches identifying new DTAFPs in nematodes. The phylogenetic relationship of six nematode Orders from two Classes (Secernentea and Adenophorea), emphasizing Rhabditida and Tylenchida ${ }^{45}$. Species containing DTAFPs are shown in red and species with their genomes completely sequenced are shadowed in yellow. Species and gene numbers are indicated in square and round brackets, respectively, in which numbers of species with completely sequenced genomes are shadowed in yellow. 
a

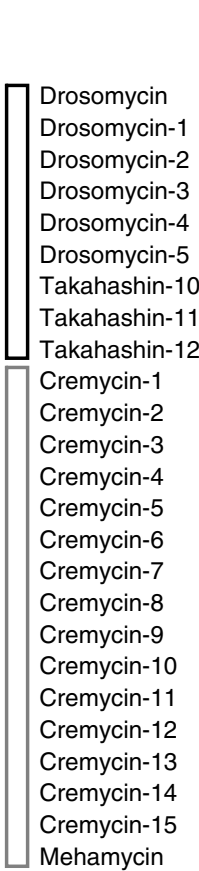

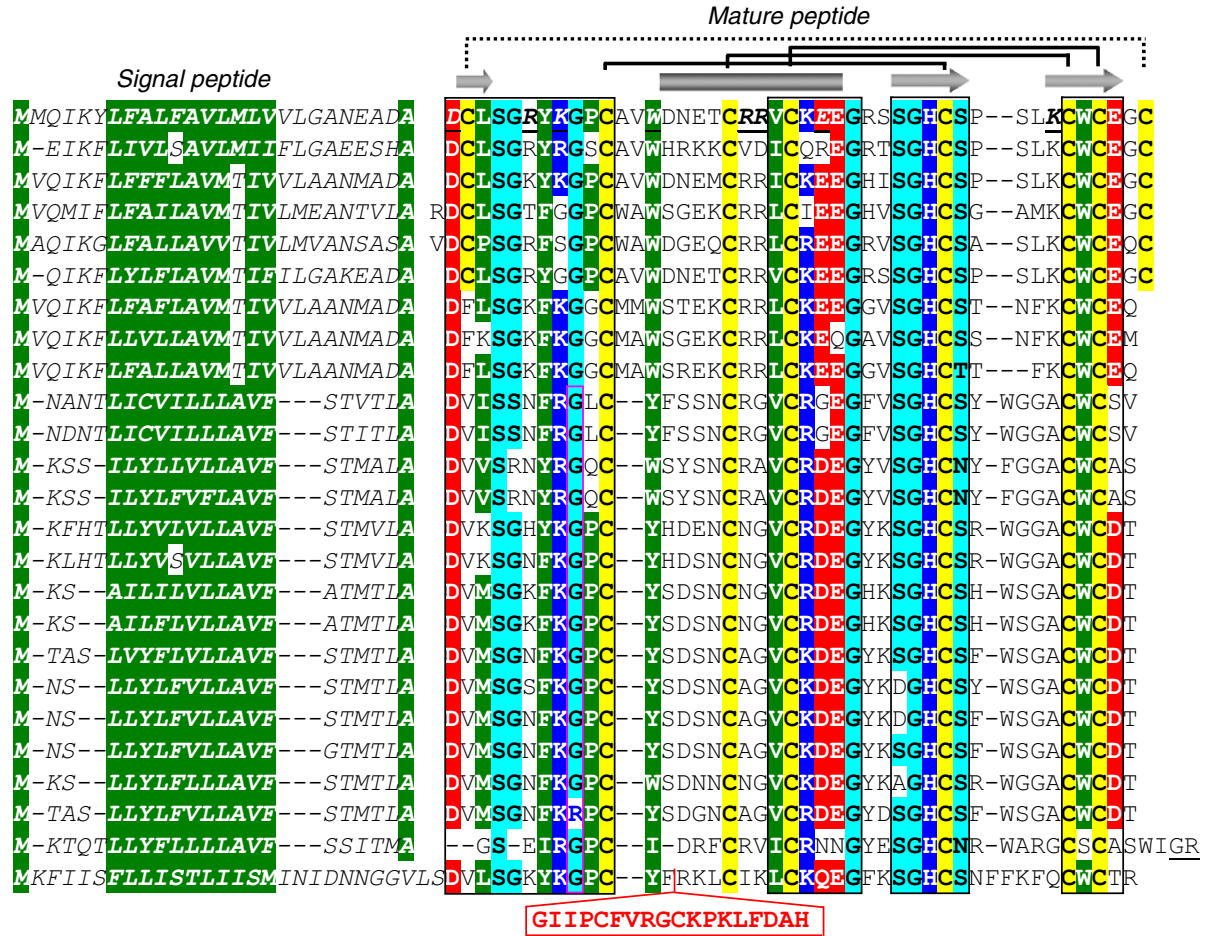

Mature peptide

b

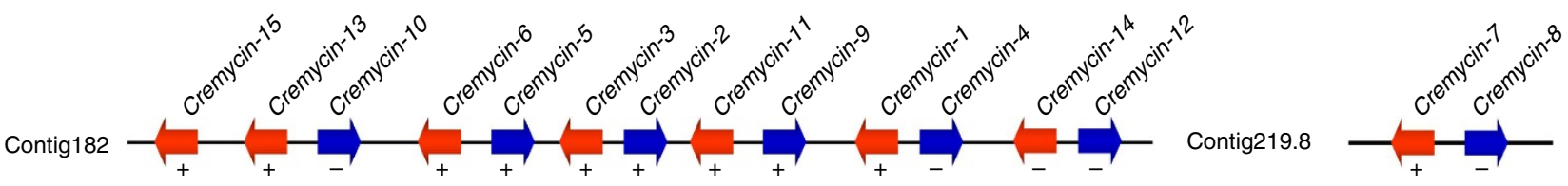

Figure 2 I DTAFPs in nematodes. (a) Multiple sequence alignment (MSA) showing evolutionary conservation of the precursor amino-acid sequences between nematode and Drosophila DTAFPs, where hydrophobic or aromatic amino acids are shadowed in green, hydrophilic residues in cyan, acidic residues and their conservative replacements in red, basic in blue and cysteines in yellow. Residues split by a positionally conserved phase- 1 intron among nematode DTAFPs are boxed in pink. Four conserved blocks across the alignment are boxed in grey. Secondary structure elements (cylinder: $\alpha$-helix; arrow: $\beta$-strand) and disulphide bridge connectivities are extracted from the structural coordinates of drosomycin (pdb entry $1 \mathrm{MNY}$ ). The dotted line represents the disulphide bridge absent in some members. Functional sites of drosomycin are italicized and underlined once. DTAFPs from Drosophila

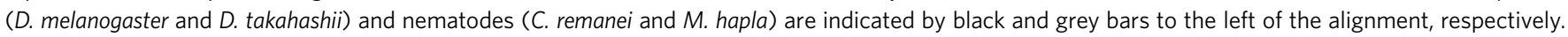
A proposed insertion in mehamycin is boxed in red; (b) the arrangement of cremycin genes in the chromosome of $C$. remanei. Arrows in different colours refer to the orientation of the genes and the sign, + or - , indicates transcription or no transcription when identified by RT-PCR (Fig. 4a).

expectation values (E-values) ranging from $3 \times 10^{-4}$ to $4 \times 10^{-11}$ (Fig. 3a). The level of significance of the $E$-values indicates that all these molecules are evolutionarily related. Clearly, cremycins are more closely related to drosomycins than to plant defensins according to their $E$-values (Fig. 3a), which is further supported by phylogenetic analysis of a total of 176 DTAFPs from C. remanei, Drosophila and plants (Supplementary Data 1). In the trees constructed by the neighbour-joining (NJ) and maximum likelihood (ML) methods, crymycins and drosomycins cluster together with high bootstrap support (Fig. 3b), in line with sequence analyses by WebLogo ${ }^{19}$ that identified 25 conserved sites between cremycins and drosomycins but only 18 such sites between cremycins and plant defensins (Fig. 3c).

Besides cremycins, we also identified a new DTAFP gene from the draft genome of $M$. hapla, a nematode species that diverged $>500$ million years ago (MYA) from Caenorhabditis ${ }^{20}$. This gene, named mehamycin, codes for a precursor with high sequence similarity to drosomycins and cremycins ( $E$-values from $1 \times 10^{-6}$ to $\left.2 \times 10^{-9}\right)$, indicating their evolutionary relationship, which is further supported by the conserved exonintron structure between mehamycin and cremycins (Fig. 2a).
Interestingly, the mature peptide of mehamycin is larger in size than that of these two classes of DTAFPs, as identified by an insertion of 18 amino acids between Cys1 and Cys2 (Fig. 2a).

Functional features of nematode DTAFPs. Reverse transcription PCR (RT-PCR) confirmed that 10 of 15 cremycin genes were transcriptionally active, in which four (cremycin-5, -9, -11 and -15) were transcribed only after challenged by the fungus Neurospora crassa (Fig. 4a). In the absence of the fungus, cremycin-3 and -6 can also be transcribed, but their transcription level was upregulated after challenge. These observations indicate that the six genes are inducible by fungi. By contrast, cremycin-7 and -13 are two constitutive genes whose expression was not affected by the challenge (Fig. 4a; Supplementary Fig. 1). In our semiquantitative RT-PCR assay, cremycin-1 and -2 co-existed in the same PCR product due to their nearly identical sequences. Similar to cremycin-7 and -13 , cremycin- 1 and -2 are also two constitutively expressed genes (Fig. 4a). Of the eight functional residues of drosomycin implicated in the interaction with fungi, seven previously identified ${ }^{7}$ and one identified here (Fig. 2a; Supplementary Fig. 2), at least one-half are conserved in 

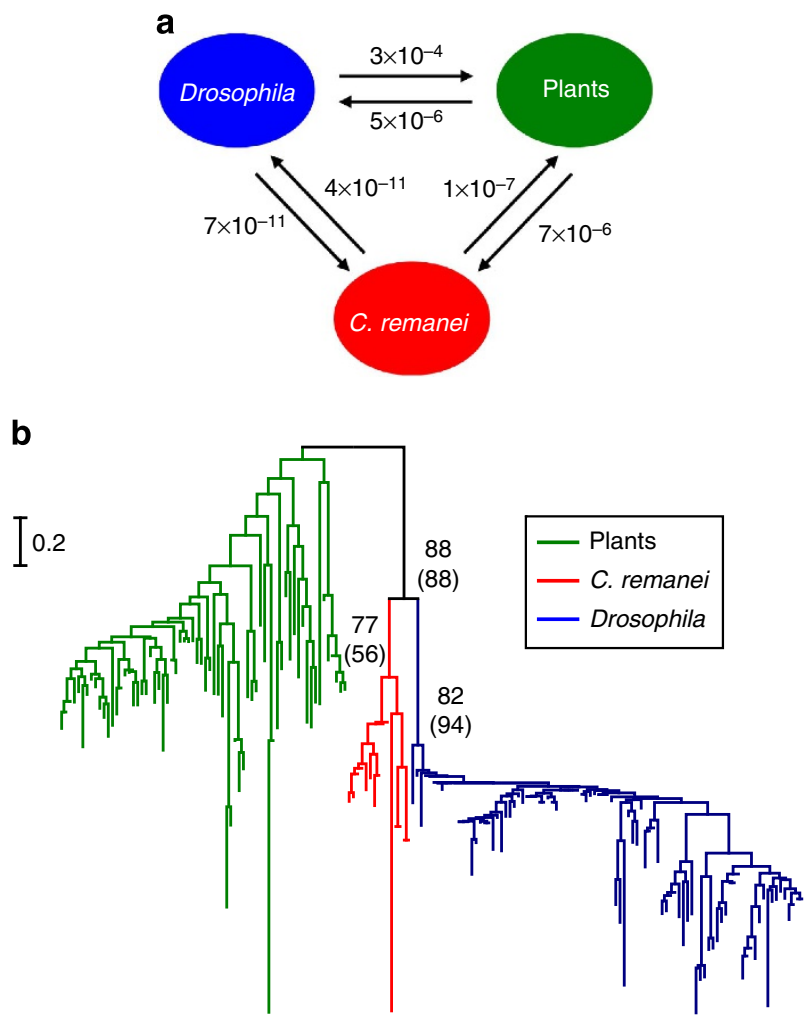

C
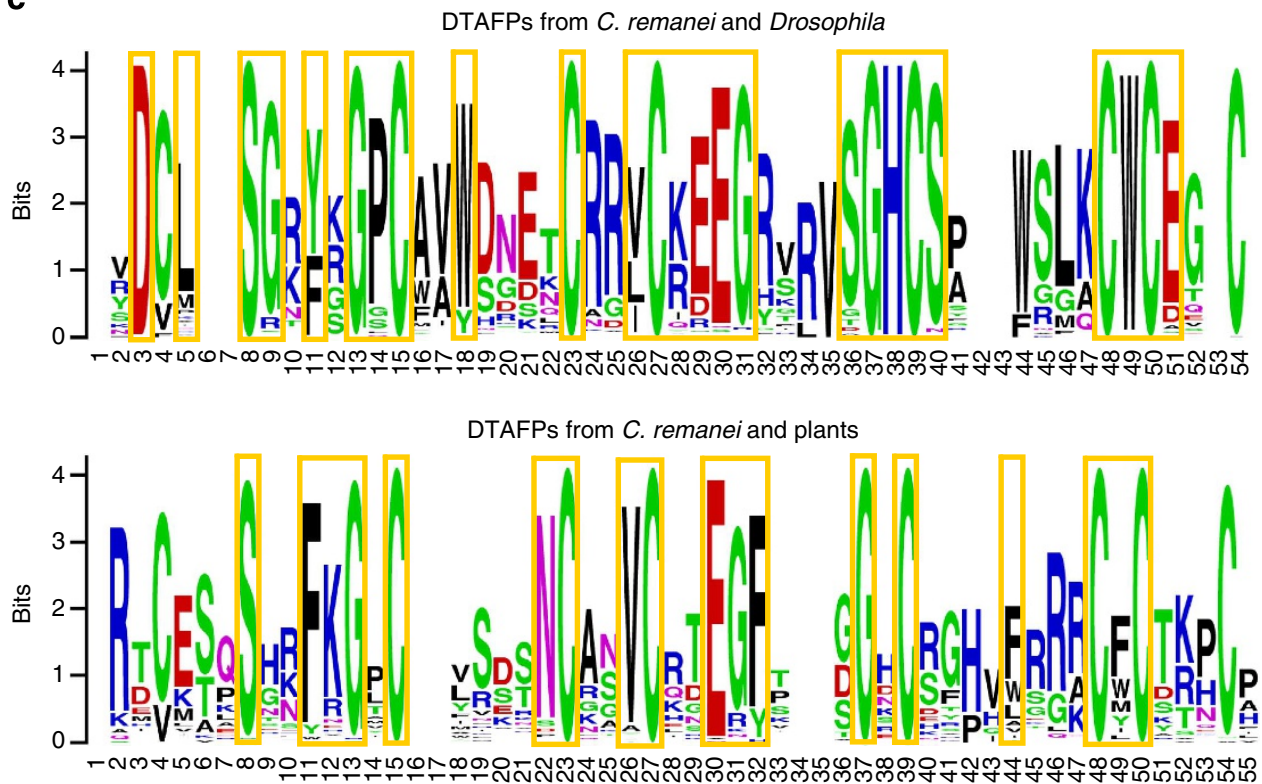

Figure 3 | Evolutionary relationship among DTAFPs from different origins. (a) Values correspond to BLAST E-values between DTAFPs from different origins. Arrows indicate the search direction; (b) the NJ tree resolving the relationship of DTAFPs. The scale bar indicates 0.2 substitutions per site. The topology of the tree is further confirmed by ML analysis with high bootstrap values ( 500 replicates) indicated in parentheses; (c) the sequence logo of DTAFPs, analysed by WebLogo ${ }^{19}$, identifying conserved sites (boxed in golden) between C. remanei and Drosophila or plants.

cremycin-1 to cremycin-14 (Fig. 4b) and only cremycin-15 exhibits more sequence divergence in the functional sites (Fig. 2a).

Cremycin-5 was selected for further functional characterization not only because it is a fungus-inducible gene but also because there was no precedent for a nematode DTAFP reported. In view of the more sequence divergence occurring between cremycin-15 and other paralogs, we also chose this peptide for a comparative study. We chemically synthesized these two peptides with a purity of more than $95 \%$, as identified by reversed-phase high-pressure liquid chromatography and MALDI-TOF MS (matrix-assisted laser desorption ionization time-of-flight mass spectrometry) (Fig. 4c; Supplementary Fig. 3). Antimicrobial assays showed that cremycin-5 and drosomycin had similar potency against the filamentous fungus $N$. crassa (Fig. 4d) with a lethal concentrations $\left(C_{\mathrm{L}}\right)$ of $0.3-0.6 \mu \mathrm{M}$ (Table 1$)$ and a peptide concentration at half-maximal inhibition efficacy $\left(\mathrm{IC}_{50}\right)$ of $0.74-0.88 \mu \mathrm{M}$. At a higher concentration $(10 \mu \mathrm{M})$ cremycin-5 damaged spores of 
a

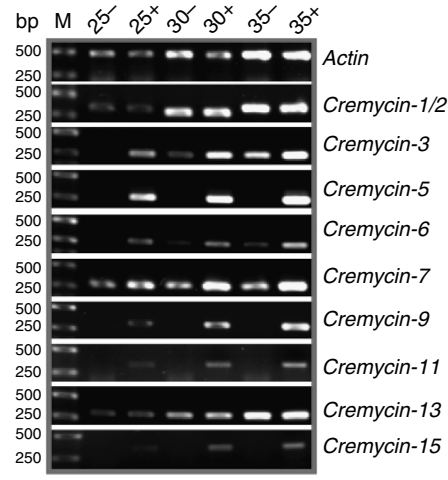

C

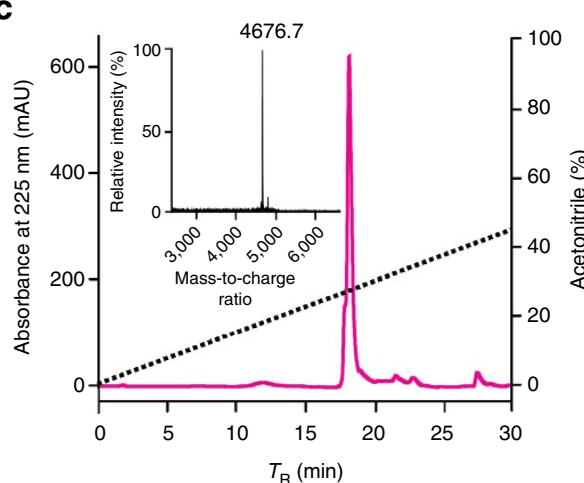

b

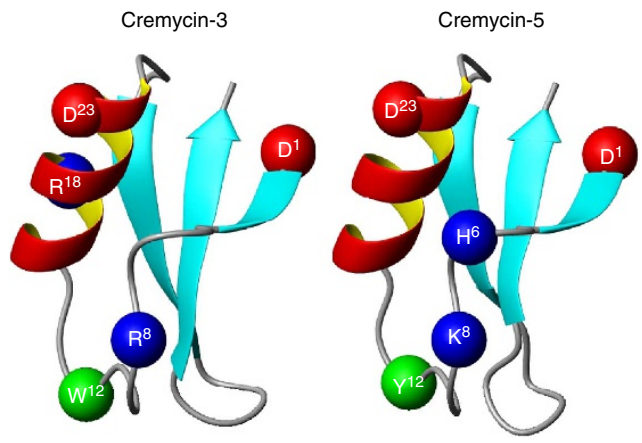

d

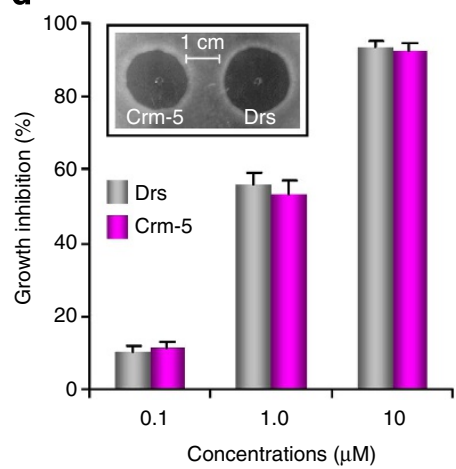

e
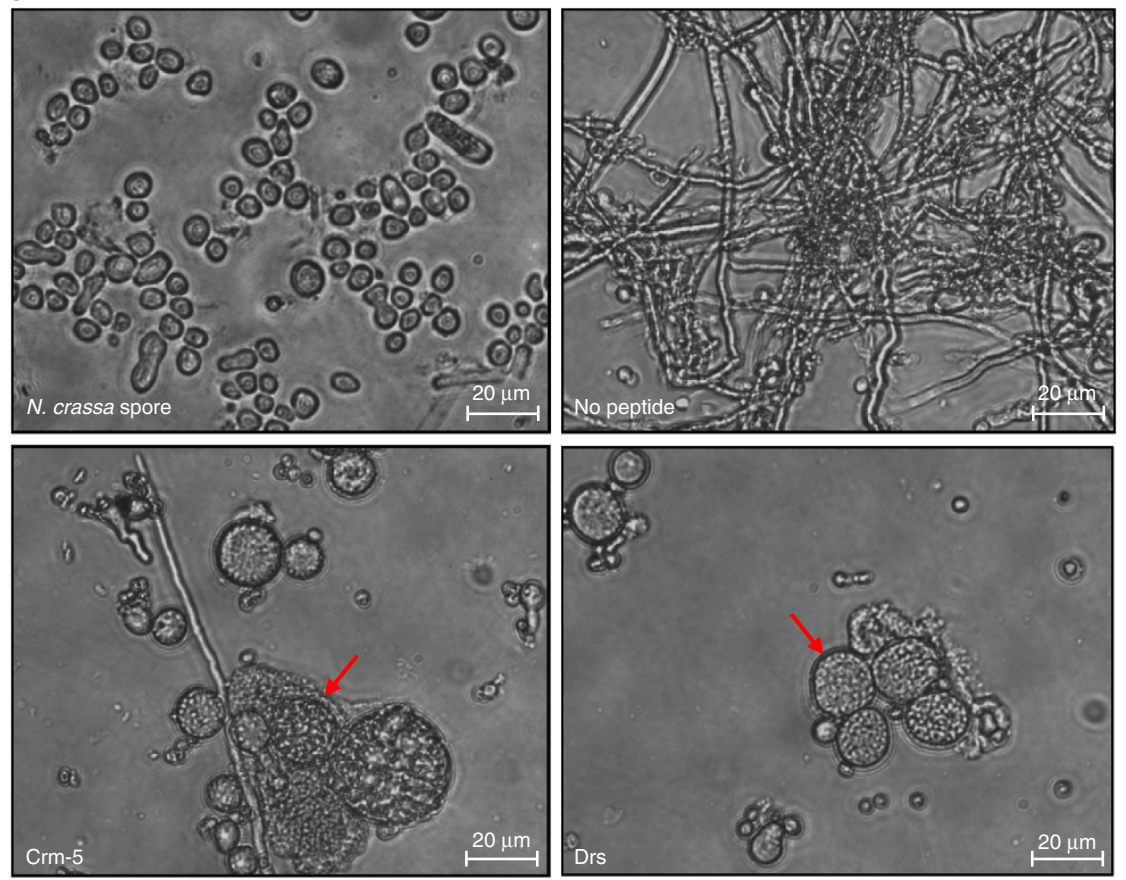

Figure 4 | Functional features of cremycins. (a) Cropped blots showing semiquantitative RT-PCR detection of the expression of cremycin genes before and after fungal challenge. The complete blots are provided in Supplementary Fig. 1. Actin was used a control. All PCR products were amplified at an annealing temperature of $62^{\circ} \mathrm{C}$. M: DNA marker. - : non-challenged; + : challenged. Numbers represent PCR cycles; (b) ribbon diagrams of two cremycin structures modelled from drosomycin at the SWISS-MODEL server ${ }^{50}$. The $\mathrm{C}_{\alpha}$ atoms of conserved residues corresponding to the functional sites of drosomycin are displayed using the Corey-Pauling-Koltun (CPK) representation; (c) reversed-phase high-pressure liquid chromatography (RP-HPLC) showing the retention time $\left(T_{R}\right)$ of chemically synthetic cremycin-5 in its oxidative form; matrix-assisted laser desorption ionization time-of-flight mass spectrometry (MALDI-TOF MS) shown in inset; (d,e) effects of cremycin-5 (Crm-5) and drosomycin (Drs) on N. crassa. (d) Concentration-dependent liquid growth inhibition. Data are expressed as mean \pm s.e. $(n=3)$. Inhibition zones formed by $0.4 \mathrm{nmol}$ of peptides each well are displayed in the inset. (e) Morphological damages of $N$. crassa spores by $10 \mu \mathrm{M}$ peptides. Photomicrographs were taken after $24 \mathrm{~h}$ of incubation of the $N$. crassa spore suspension in $1 \times$ MEA in the absence or presence of the peptides. The damaged spores are indicated by red arrows. 
Table 1 | Comparison of lethal concentrations of nematode and Drosophila DTAFPs on different fungi.

\begin{tabular}{|c|c|c|c|}
\hline & Cremycin-5 & Drosomycin & Drosomycin-2 \\
\hline Aspergillus niger & 14.9 & 1.9 & 4.9 \\
\hline Aspergillus nidulans RCho15 & 1.5 & 0.4 & N.D. \\
\hline Aspergillus nidulans RCho10 & 1.5 & 0.3 & N.D. \\
\hline Aspergillus nidulans tCho4 & 0.7 & 0.4 & N.D. \\
\hline Geotrichum candidum & 4.7 & $1.1^{\star}$ & $3.4^{\star}$ \\
\hline Neurospora crassa & 0.6 & $0.3^{\star}$ & $0.7^{\star}$ \\
\hline Candida albicans 4247 & 26.0 & N.A. & N.A. \\
\hline Candida albicans 4255 & 8.8 & N.A. & 15.0 \\
\hline Candida albicans 4257 & 10.5 & N.A. & N.A. \\
\hline Candida albicans 4258 & 12.0 & N.A. & N.A. \\
\hline Candida albicans 4259 & 23.0 & N.A. & N.A. \\
\hline Candida albicans 4277 & 14.9 & N.A. & N.A. \\
\hline Candida albicans 4286 & 8.8 & N.A. & N.A. \\
\hline Candida albicans 4287 & 1.8 & 17.2 & 9.6 \\
\hline Candida albicans 4290 & 26.0 & N.A. & N.A. \\
\hline Candida albicans B8 & 18.8 & N.A. & N.A. \\
\hline Candida albicans SZ56 & 10.5 & N.A. & N.A. \\
\hline Candida albicans SZ72 & 8.5 & N.A. & N.A. \\
\hline Candida albicans SZ90 & 8.5 & N.A. & N.A. \\
\hline Candida albicans SZ107 & 12.0 & N.A. & N.A. \\
\hline Candida albicans SZ190 & 10.9 & N.A. & N.A. \\
\hline Candida albicans SZ238 & 8.8 & N.A. & N.A. \\
\hline Candida tropicalis JX1009 & 8.8 & N.A. & N.A. \\
\hline Candida tropicalis JX1016 & 8.8 & N.A. & N.A. \\
\hline Candida tropicalis JX1017 & 8.8 & N.A. & N.A. \\
\hline Saccharomyces cerevisiae & 6.7 & $8.9^{\star}$ & $5.5^{\star}$ \\
\hline
\end{tabular}

N. crass $a$ and inhibited their germination into hyphae (Fig. 4e), a typical effect previously observed in drosomycin ${ }^{5}$. Cremycin-5 was also active on other filamentous fungi: Geotrichum candidum $\left(C_{\mathrm{L}}\right.$ : $4.7 \mu \mathrm{M})$, Aspergillus niger $\left(C_{\mathrm{L}}: 14.9 \mu \mathrm{M}\right)$, three $A$. nidulans stains $\left(C_{\mathrm{L}}: 0.7-1.7 \mu \mathrm{M}\right)$ (Table 1). Remarkably, although cremycin-5 had a similar potency to drosomycin and drosomycin-2 against the yeast Saccharomyces cerevisiae $\left(C_{\mathrm{L}}: 5.5-8.9 \mu \mathrm{M}\right)$, it exhibited more activity against two pathogenic yeasts (Candida albicans and Candida tropicalis) (Table 1). This peptide was capable of inhibiting the growth of an array of clinical isolates of these two species $\left(C_{\mathrm{L}}: 1.8-26.0 \mu \mathrm{M}\right)$. The effect of cremycin-5 on the viability of C. albicans 4287 was examined by an MTT (3-(4,5Dimethylthiazol-2-yl)-2,5-Diphenyltetrazolium Bromide)-based cytotoxicity assay that measures the mitochondrial dehydrogenase activities of live cells in the formation of MTT/formazan crystals. After treatment with $5 \times C_{\mathrm{L}}$ peptide, only $50 \%$ of the cells remained viable (Fig. 5a), indicating that the peptide is of fungicidal activity through a non-membrane disruption modes of action, as shown in Fig. 5 b.

Initial light microscopic observation suggested that cremycin-5 inhibited cytokinesis of C. albicans cells (Supplementary Fig. 4). This is further verified by the scanning electron microscopic observation, in which treated cells were not capable of dividing into two single daughter cells due to the cytokinesis inhibited and the cells displayed rough surface. On the contrary, normal C. albicans cells without the peptide lie apart and each has one to several bud scars and smooth surface (Fig. 5c). Transmission electron microscopy (TEM) showed evident damages of cellular surfaces and intracellular structure of the treated cells (Fig. 5d). Similar to drosomycins, cremycin-5 is also a strict antifungal peptide without activity on bacteria used here at $50 \mu \mathrm{M}$. This peptide was able to retain activity after $24 \mathrm{~h}$ of incubation with
$100 \%$ mouse serum and had no haemolysis even at $50 \mu \mathrm{M}$ (Supplementary Fig. 5).

In contrast to cremycin-5, cremycin-15 inhibited the growth of two Gram-positive bacteria (Bacillus megaterium and Serratia marcescens) at $C_{\mathrm{L}}$ of $14.1-17.7 \mu \mathrm{M}$, but it exhibited no activity on the fungi used here (Supplementary Table 2), implying functional diversification between paralogous cremycins after gene duplication. Despite the presence of a small insertion relative to cremycins and drosomycins, mehamycin appears to be also a functional gene because it has been confirmed to be transcriptionally active in the expressed sequence tag (EST) database (CF370770), and among the eight functional residues of drosomycin, six are conserved or conservative replacements in mehamycin (Fig. 2a).

Restricted distribution of DTAFPs in ecdysozoans. It has been previously shown that there are drosomycin-like sequences from non-Drosophila insects in the EST database, which were isolated from complementary DNA (cDNA) libraries of three coleopteran species (Callosobruchus maculates, Trox sp. JH-2005 and Agriotes lineatus $)^{10}$. To rule out potential contamination, we used C. maculates as an example to amplify its genomic DNA. As a result, we identified two positive clones, one coding for a DTAFP precursor with identical amino-acid sequence to that depicted in the EST database (C. maculates- 1 ) and another coding for a new DTAFP with several point mutations (C. maculates-3) (Fig. 6a). In addition, our BLASTP search retrieved a hit from Musca domestica that has identical sequence to drosomycin. We also confirmed its presence in the $M$. domestica genome by PCR amplification and DNA sequencing (Fig. 6b).

On the basis of the discovery of DTAFPs outside of Drosophila, we further carried out TBLASTN screen of the EST database by using drosomycins and cremycins as queries, which yielded significant hits from several non-Drosophila species. One sequence from the giant African millipede Archispirostreptus gigas (Myriapoda) exhibits $E$-values of $5 \times 10^{-4}$ to drosomycins and $7 \times 10^{-5}$ to cremycins, whereas two sequences from the Arctic springtail Onychiurus arcticus (Entognatha) exhibit $E$-values of $2 \times 10^{-6}$ to drosomycins and $9 \times 10^{-13}$ to cremycins. This new cycle of search also identified another DTAFP from the coleopteran Diabrotica virgifera virgifera (Fig. 6a).

In addition to the hits described above with significant $E$-values, some hits with low sequence similarity ( $E$-values of $2.6-9 \times 10^{-4}$ ) should also be considered as remote homologues of DTAFPs due to the similarity in structure and function, according to the criteria of Russell et al. ${ }^{21}$ All these hits are heliomicin-like antifungal peptides with a CS $\alpha \beta$-fold ${ }^{22}$. Their evolutionary relationship with DTAFPs is strengthened by the discovery that heliomicin and plant defensins interact with the same target in the fungal plasma membrane ${ }^{23}$. These newly discovered sequences are distributed in four Orders of Insecta (Arthopoda) that include Lepidoptera, Hemiptera, Neuroptera and Coleoptera, and species from Tardigrada (Fig. 6a).

Functional diversification of DTAFPs in the scorpion lineage. Our BLAST search also retrieved several scorpion toxins with similar sequences to drosomycins ( $E$-values from $1 \times 10^{-3}$ to $4 \times 10^{-6}$ ). These molecules belong to a family of scorpion toxins affecting sodium channels (Fig. 7a). They have an unusual structure that is composed of a conserved core folding into a drosomycin-like scaffold and an NC-domain comprising the $\mathrm{N}$-terminal turn (N-turn) and C-tail ${ }^{24}$ (Fig. 7b). Experimental deletion of the NC-domain of a scorpion toxin resulted in antifungal ability of the toxin ${ }^{25}$, whereas the addition of the NC-domain of a toxin on the drosomycin scaffold led to a 
a

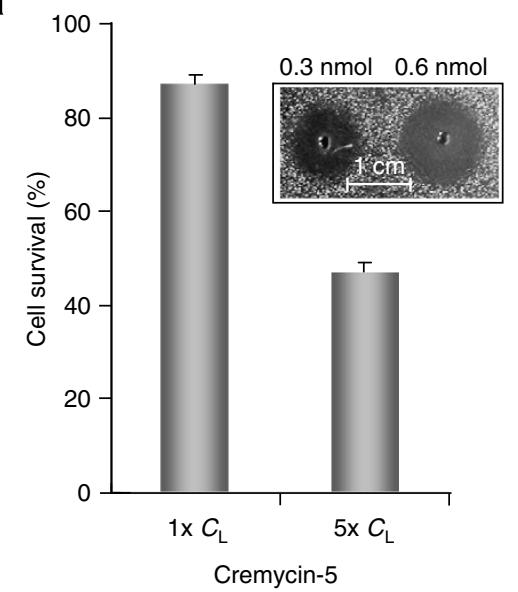

C

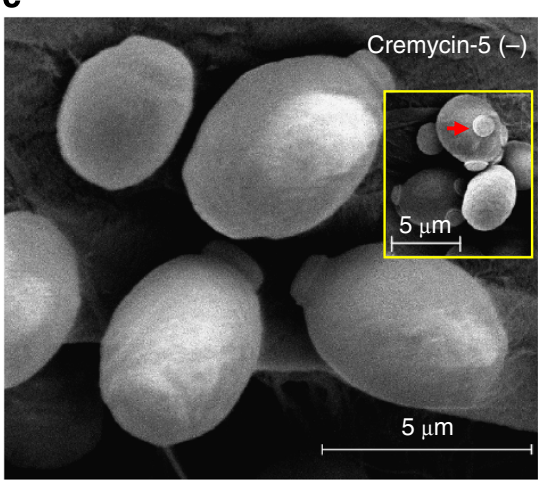

d

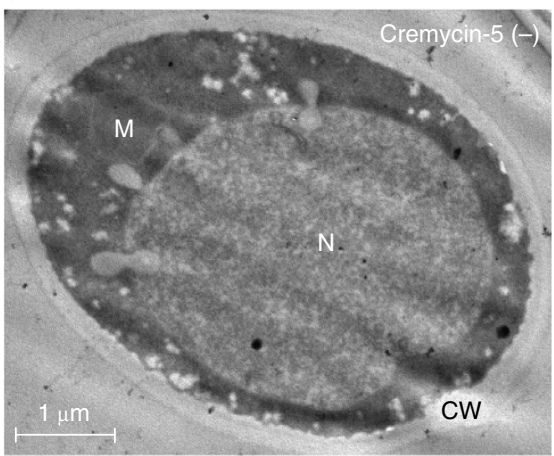

b
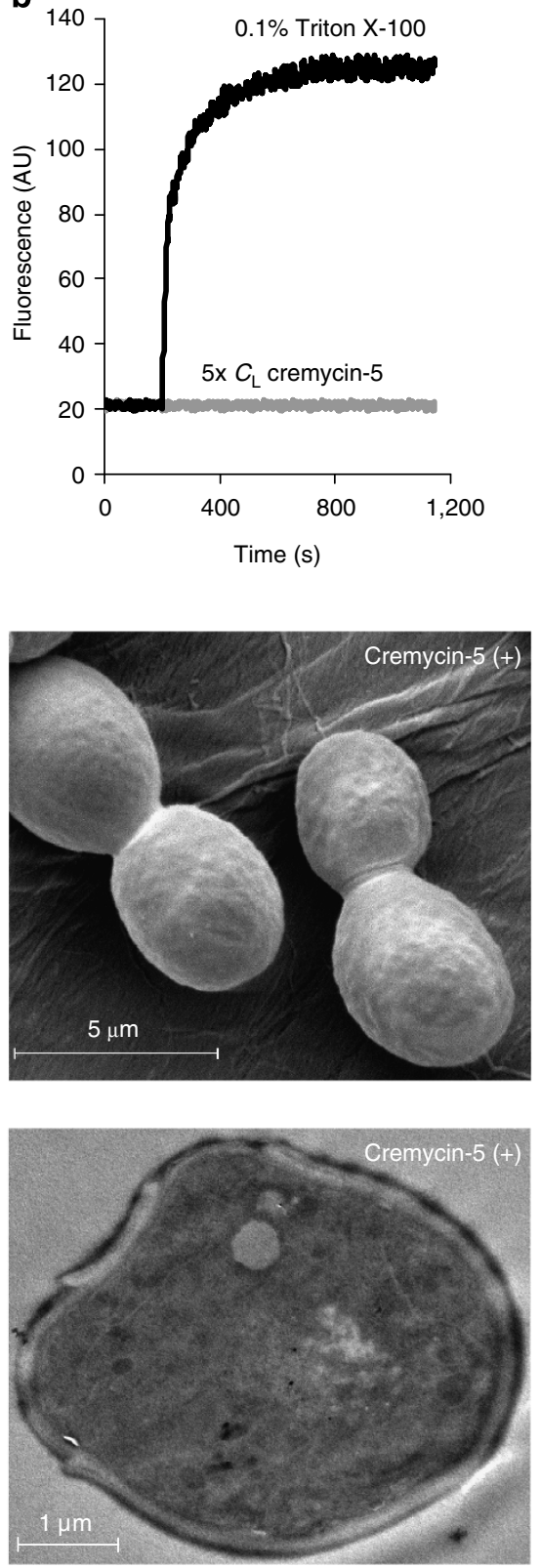

Figure 5 | Effects of cremycin-5 on C. albicans 4287. (a) Cell viability of $C$. albicans after treatment with cremycin-5, monitored using an MTT-based assay. Data are expressed as mean \pm s.e. $(n=3)$. Inhibition zones are shown in the inset; (b) effect of cremycin-5 on membrane integrity of $C$. albicans.

Triton X-100 was used as a positive control; (c) scanning electron micrographs of $C$. albicans cells in the presence and absence of cremycin-5. The red arrow indicates budding of a normal cell; (d) transmission electron microscopic observation of effects of cremycin-5 on C. albicans cells. CW, cell wall;

$M$, mitochondrion; $N$, nucleus.

neurotoxin targeting rat sodium channels ${ }^{26}$. These data provide convincing functional evidence in favour of evolutionary link between drosomycins and scorpion sodium channel toxins, and present an example of divergent evolution occurring in a specific arthropod lineage, in which a DTAFP evolved into a neurotoxin ${ }^{24-26}$. The insertion of a small fragment, as the N-turn of the scorpion toxins, in the N-terminal region of a DTAFP is also seen in mehamycin (Fig. 2a) despite its function remains to be characterized.

\section{Discussion}

In this study, we report the discovery of a multigene family of DTAFPs in a fruit nematode based on evolutionary genomics and experimental approaches. To our knowledge, this is the first report that describes functional DTAFPs in a non-Drosophila animal. The activity of cremycin-5 against a series of clinical isolates of the human pathogens (C. albicans and C. tropicalis), together with high serum stability and no haemolysis, makes it a promising therapeutic drug lead.

A combination of molecular cloning and exhaustive database searches revealed that animal DTAFPs actually have a wider phylogenetic distribution than initially thought. The most interesting finding in this work is that all species identified here possessing DTAFPs belong to the Ecdysozoa, a clade of moulting animals, which includes three phyla (Arthropoda, Nematoda and Tardigrada) ${ }^{17,27}$. The restricted presence in Ecdysozoa together with the widespread distribution in plants and the absence in 


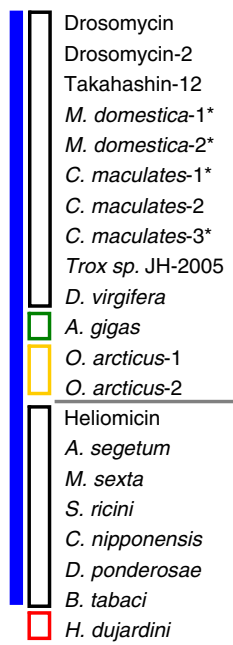

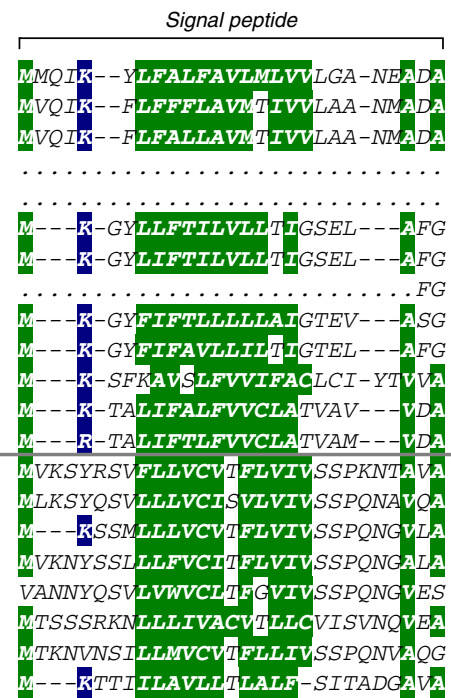

Propeptide

Mature peptide

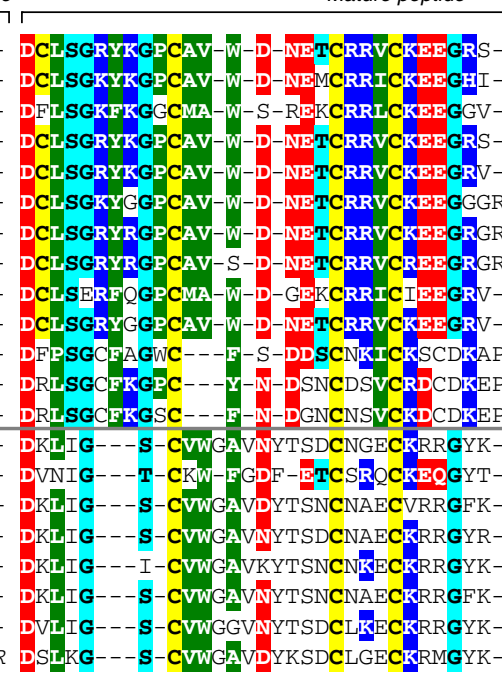

E-value

$5 \times 10^{-44}$

$1 \times 10^{-34}$

$5 \times 10^{-29}$

$9 \times 10^{-27}$

$6 \times 10^{-26}$

$2 \times 10^{-26}$

$3 \times 10^{-27}$

$5 \times 10^{-18}$

$4 \times 10^{-23}$

$4 \times 10^{-30}$

$5 \times 10^{-4}$

$2 \times 10^{-6}$

$3 \times 10^{-5}$

0.003

$9 \times 10^{-4}$

0.018

0.064

0.69

0.001

0.052

0.056 b

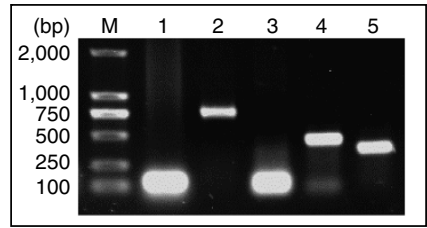

Drosomycin $\Rightarrow$

Heliomicin

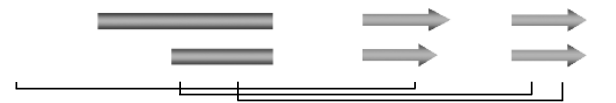

Figure 6 | New DTAFPs from non-Drosophila Arthropoda and Tardigrada. (a) MSA highlighting the conservation of amino-acid sequences. Colour codes are detailed in Fig. 2a. Secondary structure elements and disulphide bridge connectivities are extracted from structural coordinates of drosomycin and heliomicin (pdb entry 1/2U). The drosomycin and heliomicin families are distinguished by a grey line. DTAFPs from different origins are indicated by bars in colour (black: Insecta; green: Myriapoda; gold: Entognatha; red: Tardigrada; blue: Arthropoda) to the left of the alignment. '...' represents undetermined sequences. With the exception of M. domestica-1, M. domestica-2, C. maculates-3 (Supplementary Fig. 6) and C. maculates-1 (KF429250) which all are cloned in this work (indicated by ${ }^{~}{ }^{\star \prime}$ ), other non-Drosophila peptides all are retrieved from GenBank ${ }^{14}$ : C. maculates-2 (FK669231), Trox sp. JH2005 (DV767586), D. virgifera virgifera (EW769059), A. gigas (FN197359), O. arcticus-1 (EW757012), O. arcticus-2 (EW758773), heliomicin (GT206445), A. segetum (ES584181), M. sexta (ADQ00386), S. ricini (DC870370), S. ricini (DC870370), C. nipponensis (FE527725), D. ponderosae (GT484290),

B. tabaci (AGE89239), and H. dujardini (CK326749). The sequence of $A$. lineatus (CV160723) is not included here due to its incomplete mature peptide; (b) genomic amplification of drosomycin in D. melanogaster, M. domestica and C. maculates. M, DNA marker; Lane 1: D. melanogaster gDNA - drosomycin; 2: M. domestica gDNA - 28S rDNA; 3: M. domestica gDNA - drosomycin; 4: C. maculates gDNA - 28s rDNA; 5: C. maculates gDNA - drosomycin.

fungi and protozoans indicates a patch distribution pattern of this gene in eukaryotes (Fig. 8). If such a pattern is a consequence of vertical heredity, this would require that the last common ancestor of all eukaryotes evolved this gene and then it lost independently in fungi and all metazoans except ecdysozoans after the divergence of the main eukaryotic lineages. In this case, one could predict that protozoans, the early-diverged eukaryotes and the supposed common ancestor of metazoans ${ }^{28}$, would contain DTAFPs. However, a detailed survey of all the sequenced protozoan genomes of 134 species (strains) including 22 species (strains) with completely sequenced genomes (Supplementary Note 1) failed to find any significant hits. In the work of Roelofs and van Haastert ${ }^{29}$, the discovery of 11 genes shared by the protozoan Dictyostelium and human has been used as evidence to exclude HGT from bacteria to human and to support divergent evolution. The clear absence of this gene in protozoans implies that DTAFPs were not evolved in early animals.

Because of a monophyletic origin of the Ecdysozoa ${ }^{27}$, we thus believe that one HGT from plants to ecdysozoans would be by far the most favoured explanation (Fig. 8). This is highly coincided with their divergence times. It is estimated that higher plants diverged from chlorophytan green algae at $968 \pm 93 \mathrm{MYA}^{30}$ or $1061 \pm 109 \mathrm{MYA}^{31}$ and the fundamental split within higher plants occurred at the Cryogenian period $(670 \mathrm{MYA})^{32}$, earlier than an Ediacaran origin of all major ecdysozoan lineages $(\sim 587-543 \mathrm{MYA})^{33}$. It is likely that the evolution of a DTAFP first in plants, which was then transferred to the common ancestor of Ecdysozoa and subsequently diversified into its constituent phyla. This is consistent with the phylogentic tree (Fig. 3b), where DTAFPs from nematodes and Drosophila form two separate clusters but they both are closer to each other than to plant defensins. It has been shown that the nematodes frequently gained new introns during evolution ${ }^{34}$. This is the case for cremycins and mehamycin (Fig. 2a). In contrary to drosomycins that lack an intron, nematode DTAFPs gained a conserved phase- 1 intron before the divergence of $C$. remanei and M. hapla, supporting vertical evolution of this gene in nematodes. An ancient HGT followed by speciation and divergence is also observed in the aphid carotenoid synthetic genes that were presumably obtained from a fungus by $\mathrm{HGT}^{35}$. Despite this, the fact that the two nematode species with DTAFPs literally roll around decomposing plant matter in most of their reproductive lives suggests that the alternative possibility of two independent introductions of these defensive peptides to $C$. remanei and M. hapla by HGT from plants can be not completely ruled out.

It is also worth mentioning that the patch distribution of DTAFPs among the distantly related species could result from evolutionary convergence for defence against fungi. If so, this 
a

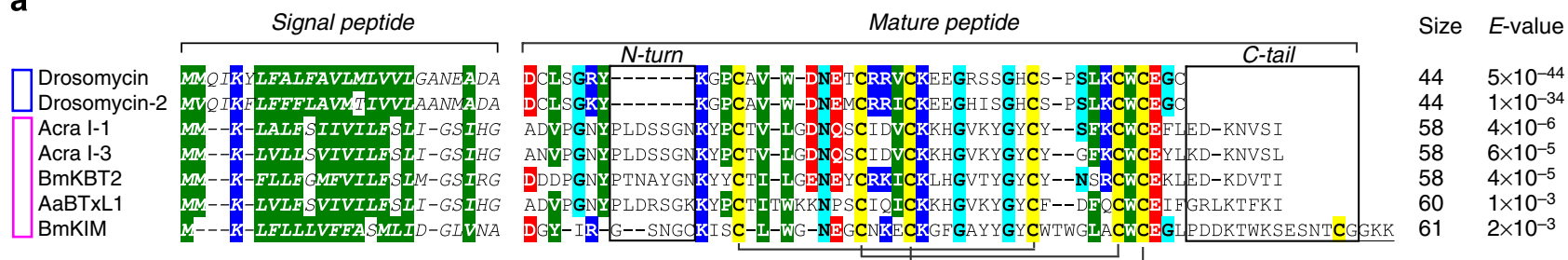

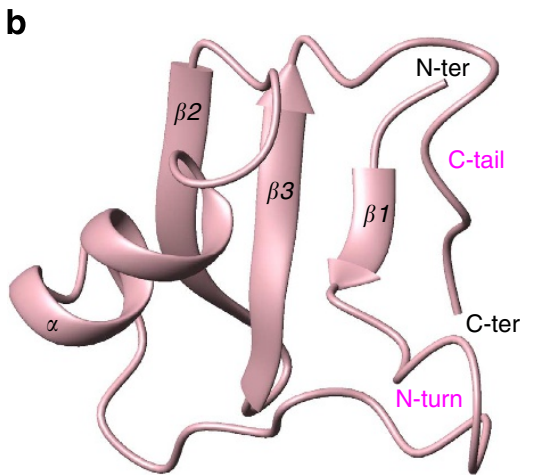

Acra I-1

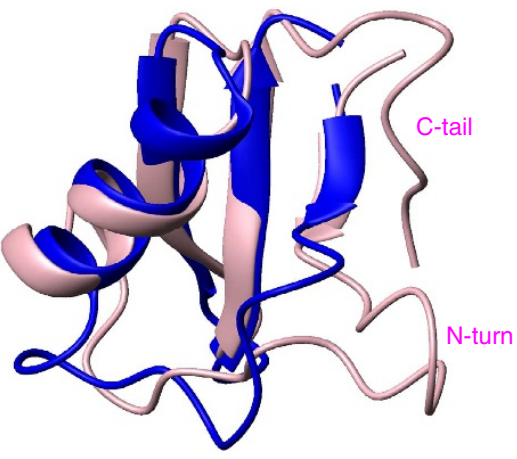

Acra I-1/Drosomycin

Figure 7 | Scorpion sodium channel toxin-like peptides are closely related to drosomycins. (a) MSA highlighting the conservation of amino-acid sequences. Colour codes are detailed in Fig. 2a. N-turn and C-tail specific in scorpion toxins are boxed; (b) structural superimposition of drosomycin and Acral-1, a toxin from the scorpion Androctonus crassicauda, highlighting the toxin-specific regions ( $\mathrm{N}$-ter and $\mathrm{C}$-ter). The model of Acral-1 was built from the structure of $\mathrm{Cn} 5$ (pdb entry $2 \mathrm{KJA}$ ), a crustacean toxin found in the venom of the scorpions C. noxius and C. suffusus suffuses ${ }^{51}$. The GenBank accession numbers of toxin sequences are Acral-1 (P0C293), Acral-3 (P0C294), BmKBT2 (AF151798), AaBTxL1 (Q4LCS8) and BmKIM (Q8IOK7).

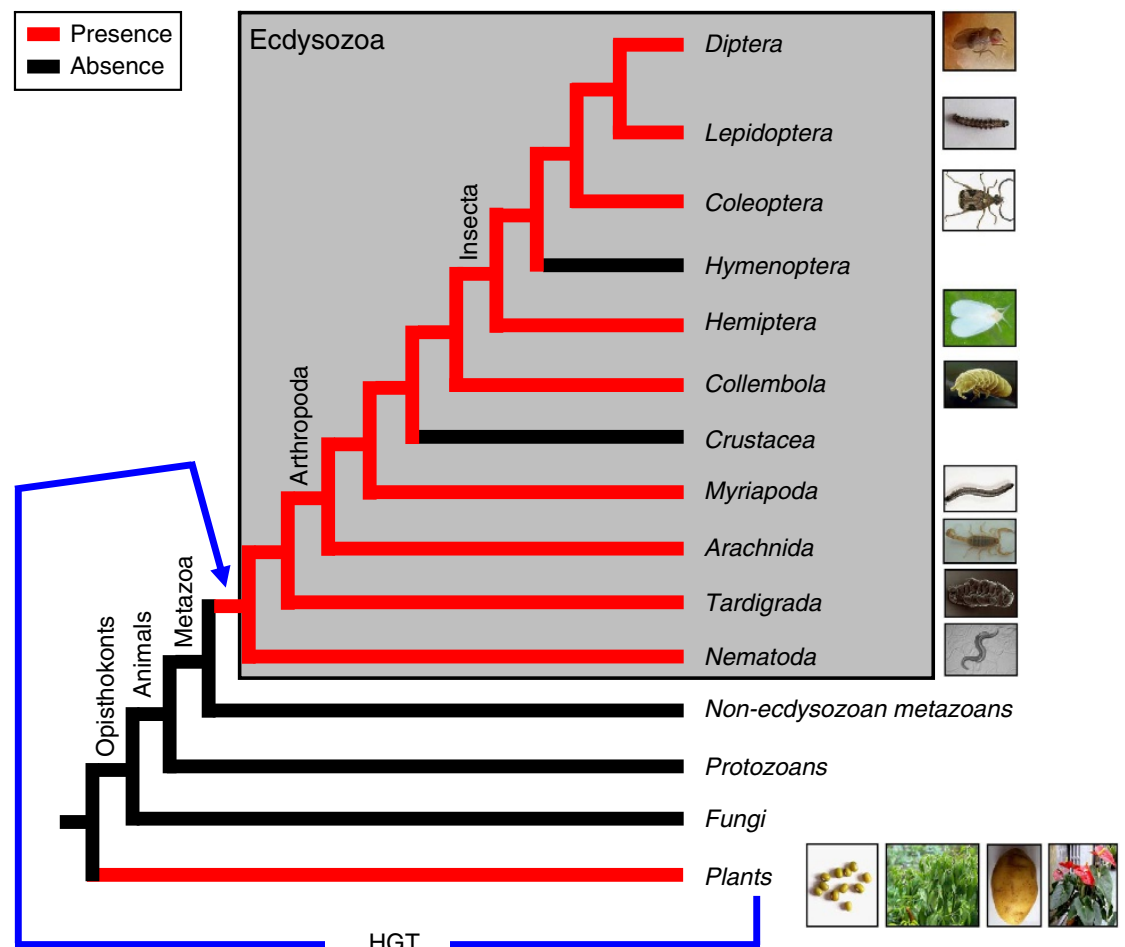

Figure 8 | Patch distribution and proposed HGT of DTAFPs. The tree of Eukaryotes is a summary of diverse sources, with emphasis on Ecdysozoa, in which branches containing species with DTAFPs are shown in red. HGT from plants to the common ancestry of Ecdysozoa is indicated by blue arrow. Photographs of C. remanei and C. maculates are kindly provided by Dr Nadine Timmermeyer and Prof. Georg Goergen, respectively.

would require that all these molecules are derived from independent genetic starting points, as in the case of a defensive peptide that has been evolved from two evolutionarily unrelated genes in two distantly related frog species $^{36}$. However, high sequence, structural and functional similarity together with identical precursor organization (a signal peptide followed by a 
mature peptide) provides more support for their evolutionary relationship other than molecular convergence. To draw a decisive conclusion on evolutionary relationship or convergence, one could need more completely sequenced genomes of ecdysozoans to investigate the precise distribution of DTAFPs.

Although present in plants and ecdysozoans, the evolution of DTAFPs appears to be more successful in plants than in ecdysozoans based on their differential phylogenetic distribution. From an ecological point of view, such evolutionary success could be due to the symbiosis of fungi and plants in natural ecosystems ${ }^{37}$ providing a selective force to maintain retention of the antifungal gene during plant evolution. This is also true for some species of ecdysozoans, such as Drosophila and C. remanei, which both live in fungi-rich rotting fruits ${ }^{1,16}$ and thus facilitates the retention of multiple DTAFP genes in their genomes. However, some other species of insects and nematodes have lost this gene, as evidenced by the absence of any orthologs in their completely sequenced genomes, such as Nasonia vitripennis, Apis mellifera, Bombus terrestris, Anopheles gambiae, Tribolium castaneum, C. elegans, and C. briggsae. The loss of DTAFPs in these species suggests its poor fixation during ecdysozoan evolution. This could be partly explained by the absence of selective pressure in several insects that live in a fungi-poor environment, such as $N$. vitripennis and A. gambiae. In fact, the lack of microbes in its niches has been considered as a cause leading to the loss of many antimicrobial genes during aphid evolution $^{38}$. However, considering key immune roles of DTAFPs in resisting fungal infection ${ }^{6,11}$, the loss of this gene in two sibling species of C. remanei (C. elegans and C. briggsae) is puzzling as they also live in fungi-rich habitats. A potential explanation is that these two nematode species could mount an alternative, but equal, antifungal genes. In fact, microarray-based transcriptional profiling of infected worms combined with computational approaches has identified seven fungus-induced peptide (fip) genes and 29 fip-related genes in C. elegans ${ }^{39}$. Alternatively, differential fixation of DTAFPs in different species of Caenorhabditis could be a reflection of their diverse ecologies ${ }^{40}$. For example, despite C. elegans and C. briggsae both exist in large, proliferating populations in rotting fruits and stems, their temporal distributions do not coincide $^{41}$. In addition, C. remanei and the two sibling species exhibit totally different reproduction modes. Different from the gonochoristic C. remanei, C. elegans and C. briggsae have evolved a self-fertile hermaphroditic mode. Because evolutionary transitions between sexual modes are potent forces in genome evolution ${ }^{42}$, this could be another cause for the differential fixation of the gene in these three species. The absence of DTAFPs in C. elegans and C. briggsae is consistent with the genome shrinkage in these two selfing species ${ }^{42}$.

Extensive gene duplication to assemble a multigene family is a typical feature observed in many genes transferred to the nematode genomes ${ }^{43}$. In plants and the ecdysozoans with this gene, most of DTAFPs also exist as multigene families and some have evolved novel biological functions. For example, in addition to major antifungal activity, some plant DTAFPs have developed diverse activities as inhibitors of protein translation, enzymes and bacterial growth, mediators of zinc tolerance, and blockers of ion channels ${ }^{4}$. Similarly, drosomycin has been found to gain ability in interacting with the fly voltage-gated sodium channel, possibly acting as a neuropeptide ${ }^{25}$. In C. remanei, cremycin-15 has evolved antibacterial activity described here, while scorpion venom-derived DTAFPs have switched their targets from fungi to animal sodium channels ${ }^{24-26}$. All these observations suggest that the gene can be fixed only in organisms where it developed important functions following gene duplication and speciation.
In conclusion, our work has revealed a complex evolutionary history of DTAFPs, in which an ancient HGT from plants led to the origin of a disease resistance gene in a specific animal clade and subsequent vertical inheritance involving gene duplication, loss and functional diversification shaped this gene family in ecdysozoans. Our discovery might be also valuable in guiding the discovery of new DTAFPs with therapeutic potential from other ecdysozoans living in fungi-rich niches.

\section{Methods}

Database search. To find new DTAFPs, we first used the amino-acid sequences of drosomycins and plant defensins as queries to perform TBLASTN search of the genomic BLAST databases in GenBank under default parameters ${ }^{14}$. The database contains 20 species of Nematoda with two genomes completely sequenced (C. briggsae and C. elegans) (Supplementary Note 1). These species belong to five Orders of Class Secernentea (Ascaridida, Spirurida, Tylenchida, Rhabditida and Diplogasterida) and one Order of Class Adenophalida ${ }^{45}$ (Trichocephalida). The database also contains 62 species of the Phylum Arthropoda with ten completely sequenced insect genomes (Anopheles gambiae str. PEST, D. melanogaster,

D. pseudoobscura pseudoobscura, D. simulans, D. yakuba, Tribolium castaneum, Apis mellifera, Bombus terrestris, Nasonia vitripennis, and Acyrthosiphon pisum) (Supplementary Note 1). Using the same approaches presented here, we also searched other databases in GenBank, which include the nucleotide collection (nr/ nt) database, the EST database, and the reference genomic sequences

(refseq_genomic) database ${ }^{14}$. The database $E$-values were calculated by the BLAST programs using the equation: $E=N / 2^{S^{\prime}}$, where $N$ is the total length of the database in residues and $S^{\prime}$ is the normalized score for a high-scoring segment pair (HSP) ${ }^{46}$.

Phylogenetic tree constructions. Amino-acid sequences of DTAFPs from Drosophila, C. remanei and plants (Supplementary Data 1) were aligned by ClustalX, which were then used to construct phylogenetic trees by the NJ and ML methods in MEGA 5.0 (ref. 47), on the basis of the Jones-Taylor-Thornton substitution model with a gamma distribution of rates between sites. In ML analysis, an initial tree was first built automatically with the NJ method and then variants of the topology were created with the nearest neighbour interchange method to search for topologies for fitting the data better. Five hundred bootstrap replicates were performed in the NJ and the ML tree.

Gene cloning and semiquantitative RT-PCR. The TRIZOL reagent (SBS Genetech, Beijing) was used to prepare total RNA of C. remanei strain PB4641 according to the supplier's instructions. Reverse transcription of mRNAs into the first-strand cDNAs was performed using EasyScript First-Strand cDNA Synthesis Kit (TransGen Biotech., Beijing) that was used as template for PCR amplification. PCR products were ligated into the pGM-T Vector and recombinant plasmids were transformed into Escherichia coli DH5a. Positive clones were sequenced with T7 or SP6 primer. Nucleotide sequences of cremycin-1, cremycin-2, cremycin-3, cremycin5 , cremycin-6, cremycin-7, cremycin-9, cremycin-11, cremycin-13, and cremycin-15 have been deposited in the GenBank database under the accession numbers JN230817-JN230826, respectively.

For semiquantitative RT-PCR, a cremycin gene was amplified from nonchallenged cDNAs of C. remanei strain PB4641 or N. crassa-challenged cDNAs by a gene-specific primer and 3AP. PCR products obtained from different cycles $(25$, 30 and 35) were taken for comparison of the amounts of these products. The C. remanei actin was chosen as an internal control that was amplified by primers CRM-actin/3AP and the same cDNA templates. Primers are provided in Supplementary Table 2.

Chemical synthesis and oxidative refolding. Cremycin- 5 and cremycin- 15 were chemically synthesized in their reduced form by ChinaPeptides Co. Ltd. (Shanghai, China). For oxidative refolding, peptide samples were dissolved in $0.1 \mathrm{M}$ Tris- $\mathrm{HCl}$ buffer $\left(\mathrm{pH} \mathrm{8.5)}\right.$ to a final concentration of $1 \mathrm{mM}$ and incubated at $25^{\circ} \mathrm{C}$ for $48 \mathrm{~h}$. Peptides were purified to homogeneity by reversed-phase high-pressure liquid chromatography using a $\mathrm{C}_{18}$ column. The column was equilibrated with $0.1 \%$ trifluoroacetic acid and purified products were eluted from the column with a linear gradient from $0 \%$ to $60 \%$ acetonitrile in $0.1 \%$ trifluoroacetic acid within $40 \mathrm{~min}$. Molecular mass of peptides were determined by MALDI-TOF MS on a Kratos PC Axima CFR plus (Shimadzu Co. LTD, Kyoto, Japan).

Antimicrobial assays. For inhibition zone assays, fungi were incubated on $1 \times$ MEA (malt extract agar) plate at $28^{\circ} \mathrm{C}$ for 1 week. Spores were harvested and suspended in sterile water with an $\mathrm{OD}_{595}$ of 0.5 . Six $\mathrm{ml}$ of $1 \times$ MEA containing $0.8 \%$ agarose was mixed with $50 \mu \mathrm{l}$ spores suspension and poured into one Petri dish of $9.0 \mathrm{~cm}$ in diameter. Wells with a diameter of $3 \mathrm{~mm}$ were punched into the medium, filled with $2 \mu \mathrm{l}$ of sample each well. The plate was incubated in dark at $28^{\circ} \mathrm{C}$ for $24 \mathrm{~h}$. Similar procedures were also used in antibacterial assays, in which MEA was replaced by Luria Broth medium and the incubation temperature was 
$37^{\circ} \mathrm{C}$ instead of $28^{\circ} \mathrm{C}$. $C_{\mathrm{L}}$ of peptides was determined by the inhibition-zone assays and $\mathrm{IC}_{50}$ was defined as peptide concentration leading to $50 \%$ of fungal growth inhibition ${ }^{48}$. The sources of the microorganisms used in this assay are listed in Supplementary Table 3.

Haemolytic effect and serum stability. Haemolytic effects of peptides against fresh mouse erythrocytes were assayed according to the standard method ${ }^{49}$. To assess serum stability, peptides were incubated in water or fresh mouse serum for 0 , $1,3,6$ and $24 \mathrm{~h}$ at $28^{\circ} \mathrm{C}$. Residual activities on $N$. crassa were measured by the inhibition zone assays.

MTT assay. To determine the viability of C. albicans cells treated by cremycin-5, the cells were incubated with MTT for $4 \mathrm{~h}$. Pellets collected by centrifugation were dissolved in $200 \mu \mathrm{l}$ dimethyl sulfoxide, and cell viability was measured at $570 \mathrm{~nm}$ by the VersaMax reader (Molecular Devices).

Membrane permeability assay. To assess the permeation ability of cremycin- 5 on C. albicans cells, $5 \times 10^{5}$ cells in $500 \mu$ l of phosphate-buffered saline (PBS) were mixed with propidium iodide to a final concentration of $1 \mu \mathrm{M}$ for $5 \mathrm{~min}$ in the dark. After peptide was added, the absorbance was measured by a F-4500 fluorescence spectrophotometer (Hitachi High-Technology Company). Once basal fluorescence reached a constant value, cremycin-5 or Triton X-100 was added. Changes in fluorescence absorbance were monitored and plotted as arbitrary units.

Electron microscopy. C. albicans cells were treated with cremycin-5 at $5 \times C_{\mathrm{L}}$ at $30^{\circ} \mathrm{C}$ for $90 \mathrm{~min}$ and were then fixed with $2.5 \%$ glutaraldehyde for $1 \mathrm{~h}$ and washed three times with PBS. For scanning electron microscopy (SEM), cells were dehydrated with a series of graded ethanol solution and then dried by BAL-TEC CPD030 critical point dryer before being mounted on carbon tape, sputtered with platinum coating (BAL-TEC SCD005). Images were visualized in FEI QUANTA 200. For TEM, cells were postfixed with $1 \%$ osmium tetroxide for $1 \mathrm{~h}$. After washed twice with PBS, cells were dehydrated with a series of graded ethanol solution and then embedded in EPON 812 resin. Ultrathin sections were obtained by Leica EM UC6 t FC6 and stained with uranyl acetate and lead citrate. Images were visualized in a Tecnai Spirit $120 \mathrm{KV}$ microscope.

\section{References}

1. Trienens, M., Keller, N. P. \& Rohlfs, M. Fruit, flies and filamentous fungi experimental analysis of animal-microbe competition using Drosophila melanogaster and Aspergillus mould as a model system. Oikos 119, 1765-1775 (2010).

2. Hoffmann, J. A. \& Reichhart, J. M. Drosophila innate immunity: an evolutionary perspective. Nat. Immunol. 3, 121-126 (2002).

3. Zhang, Z. \& Zhu, S. Drosomycin, an essential component of antifungal defence in Drosophila. Insect Mol. Biol. 18, 549-556 (2009).

4. Khush, R. S. \& Lemaitre, B. Genes that fight infection: what the Drosophila genome says about animal immunity. Trends. Genet. 16, 442-449 (2000).

5. Fehlbaum, P. et al. Septic injury of Drosophila induces the synthesis of a potent antifungal peptide with sequence homology to plant antifungal peptides. J. Biol. Chem. 269, 33159-33163 (1994).

6. Lemaitre, B., Nicolas, E., Michaut, L., Reichhart, J. M. \& Hoffmann, J. A. The dorsoventral regulatory gene cassette spätzle/Toll/cactus controls the potent antifungal response in Drosophila adults. Cell 86, 973-983 (1996).

7. Zhang, Z. \& Zhu, S. Functional role of charged residues in drosomycin, a Drosophila antifungal peptide. Dev. Comp. Immunol. 34, 953-958 (2010).

8. Bloch, C. et al. ${ }^{1} \mathrm{H}$ NMR structure of an antifungal $\gamma$-thionin protein SI $\alpha 1$ : similarity to scorpion toxins. Proteins 32, 334-349 (1998).

9. Landon, C., Sodano, P., Hetru, C., Hoffmann, J. \& Ptak, M. Solution structure of drosomycin, the first inducible antifungal protein from insects. Protein Sci. 6, 1878-1884 (1997).

10. Sackton, T. B. et al. Dynamic evolution of the innate immune system in Drosophila. Nat. Genet. 39, 1461-1468 (2007).

11. Carvalho Ade, O. \& Gomes, V. M. Plant defensins and defensin-like peptides biological activities and biotechnological applications. Curr. Pharm. Des. 17, 4270-4293 (2011).

12. Zhu, S. Discovery of six families of fungal defensin-like peptides provides insights into origin and evolution of the CS $\alpha \beta$ defensins. Mol. Immunol. 45, 828-838 (2008).

13. Gao, B. \& Zhu, S. Differential potency of drosomycin to Neurospora crassa and its mutant: implications for evolutionary relationship between defensins from insects and plants. Insect Mol. Biol. 17, 405-411 (2008).

14. Benson, D. A. et al. GenBank. Nucleic Acids Res. 41, D36-D42 (2013).

15. Zhaxybayeva, O. \& Doolittle, W. F. Lateral gene transfer. Curr. Biol. 21, R242-R246 (2011)

16. Kiontke, K. C. et al. A phylogeny and molecular barcodes for Caenorhabditis, with numerous new species from rotting fruits. BMC Evol. Biol. 11, 339 (2011).
17. Aguinaldo, A. M. A. et al. Evidence for a clade of nematodes, arthropods and other moulting animals. Nature 387, 489-493 (1997).

18. Martin-Eauclaire, M. F. et al. Molecular cloning and nucleotide sequence analysis of a cDNA encoding the main beta-neurotoxin from the venom of the South American scorpion Tityus serrulatus. FEBS Lett. 302, 220-222 (1992).

19. Crooks, G. E., Hon, G., Chandonia, J. M. \& Brenner, S. E. WebLogo: a sequence logo generator. Genome Res. 14, 1188-1190 (2004).

20. Opperman, C. H. et al. Sequence and genetic map of Meloidogyne hapla: A compact nematode genome for plant parasitism. Proc. Natl Acad. Sci. USA 105, 14802-14807 (2008)

21. Russell, R. B., Saqi, M. A. S., Sayle, R. A., Bates, P. A. \& Sternberg, M. J. E. Recognition of analogous and homologous protein folds: analysis of sequence and structure conservation. J. Mol. Biol. 269, 423-439 (1997).

22. Lamberty, M. et al. Solution structures of the antifungal heliomicin and a selected variant with both antibacterial and antifungal activities. Biochemistry 40, 11995-12003 (2001).

23. Thevissen, K. et al. Defensins from insects and plants interact with fungal glucosylceramides. J. Biol. Chem. 279, 3900-3905 (2004).

24. Zhu, S., Gao, B. \& Tytgat, J. Phylogenetic distribution, functional epitopes and evolution of the CS $\alpha \beta$ superfamily. Cell Mol. Life Sci. 62, 2257-2269 (2005).

25. Cohen, L. et al. Drosomycin, an innate immunity peptide of Drosophila melanogaster, interacts with the fly voltage-gated sodium channel. J. Biol. Chem. 284, 23558-23563 (2009)

26. Zhu, S. et al. Drosotoxin, a selective inhibitor of tetrodotoxin-resistant sodium channels. Biochem. Pharmacol. 80, 1296-1302 (2010).

27. Telford, M. J., Bourlat, S. J., Economou, A., Papillon, D. \& Rota-Stabelli, O The evolution of the Ecdysozoa. Phil. Trans. R. Soc. B 363, 1529-1537 (2008).

28. King, N. The unicellular ancestry of animal development. Dev. Cell 7, 313-325 (2004).

29. Roelofs, J. \& Van Haastert, P. J. M. Genes lost during evolution. Nature 411, 1013-1014 (2001).

30. Hedges, S. B., Blair, J. E., Venturi, M. L. \& Shoe, J. L. A molecular timescale of eukaryote evolution and the rise of complex multicellular life. BMC Evol. Biol. 4, 2 (2004).

31. Heckman, D. S. et al. Molecular evidence for the early colonization of land by fungi and plants. Science 293, 1129-1133 (2001).

32. Clarke, J. T., Warnock, R. C. \& Donoghue, P. C. Establishing a time-scale for plant evolution. New Phytol. 192, 266-301 (2011).

33. Rota-Stabelli, O., Daley, A. C. \& Pisani, D. Molecular timetrees reveal a Cambrian colonization of land and a new scenario for ecdysozoan evolution. Curr. Biol. 23, 392-398 (2013).

34. Coghlan, A. \& Wolfe, K. H. Origins of recently gained introns in Caenorhabditis. Proc. Natl Acad. Sci. USA 101, 11362-11367 (2004).

35. Moran, N. A. \& Jarvik, T. Lateral transfer of genes from fungi underlies carotenoid production in aphids. Science 328, 624-627 (2010).

36. Roelants, K. et al. Identical skin toxins by convergent molecular adaptation in frogs. Curr. Biol. 20, 125-130 (2010).

37. Venkateshwaran, M., Volkening, J. D., Sussman, M. R. \& Ané, J. M. Symbiosis and the social network of higher plants. Curr. Opin. Plant Biol. 16, 118-127 (2013).

38. Gerardo, N. M. Immunity and other defenses in pea aphids Acyrthosiphon pisum. Genome Biol. 11, R21 (2010).

39. Pujol, N., Davis, P. A. \& Ewbank, J. J. The origin and function of anti-fungal peptides in C. elegans: open questions. Front Immunol. 3, 237 (2012).

40. Kiontke, K. \& Sudhaus, W. Ecology of Caenorhabditis species. WormBook 9, 1-14 (2006)

41. Félix, M. A. \& Duveau, F. Population dynamics and habitat sharing of natural populations of Caenorhabditis elegans and C. briggsae. BMC Biol. 10, 59 (2012).

42. Thomas, C. G. et al. Simplification and desexualization of gene expression in self-fertile nematodes. Curr. Biol. 22, 2167-2172 (2012).

43. Danchin, E. G. et al. Multiple lateral gene transfers and duplications have promoted plant parasitism ability in nematodes. Proc. Natl Acad. Sci. USA 107, 17651-17656 (2010).

44. Carvalho Ade, O. \& Gomes, V. M. Plant defensins--prospects for the biological functions and biotechnological properties. Peptides 30, 1007-1020 (2009).

45. Blaxter, M. L. et al. A molecular evolutionary framework for the phylum Nematoda. Nature 392, 71-75 (1998).

46. Altschul, S. F., Gish, W., Miller, W., Myers, E. W. \& Lipman, D. J. Basic local alignment search tool. J. Mol. Biol. 215, 403-410 (1990).

47. Tamura, K. et al. MEGA5: molecular evolutionary genetics analysis using maximum likelihood, evolutionary distance, and maximum parsimony methods. Mol. Biol. Evol. 28, 2731-2739 (2011). 
48. Tian, C. et al. Gene expression, antiparasitic activity, and functional evolution of the drosomycin family. Mol. Immunol. 45, 3909-3916 (2008).

49. Zhu, S., Gao, B., Harvey, P. \& Craik, D. Dermatophytic defensin with antiinfective potential. Proc. Natl Acad. Sci. USA 109, 8495-8500 (2012)

50. Arnold, K., Bordoli, L., Kopp, J. \& Schwede, T. The SWISS-MODEL Workspace: A web-based environment for protein structure homology modelling. Bioinformatics 22, 195-201 (2006).

51. Corzo, G., Prochnicka-Chalufour, A., García, B. I., Possani, L. D. \& Delepierre, M. Solution structure of $\mathrm{Cn} 5$, a crustacean toxin found in the venom of the scorpions Centruroides noxius and Centruroides suffusus suffus. Biochim. Biophys. Acta. 1794, 1591-1598 (2009).

\section{Acknowledgements}

We thank Prof. Scott Baird for providing C. remanei strain PB4641 for RNA preparation; Lei Sun (Lab of Bio-imagine, Institute of Biophysics) for her help in making TEM samples and taking TEM images; Mr. Yucheng Wu for preparing the drosomycin mutant (W14A). This work was supported by the National Basic Research Program of China (2010CB945300), the National Natural Science Foundation of China (31221091) and the State Key Laboratory of Integrated Management of Pest Insects and Rodents (Grant No. ChineseIPM1307).

\section{Author contributions}

S.Z. designed the research, performed all evolutionary analyses and wrote the paper. B.G. did the molecular, biochemical and functional studies. All authors reviewed, revised and approved the manuscript.

\section{Additional information}

Accession codes: Nucleotide sequences of cremycin-1, cremycin-2, cremycin-3, cremycin5, cremycin-6, cremycin-7, cremycin-9, cremycin-11, cremycin-13, and cremycin-15 have been deposited in the GenBank/EMBL/DDBJ nucleotide core database under accession codes JN230817 to JN230826.

Supplementary Information accompanies this paper at http://www.nature.com/ naturecommunications

Competing financial interests: The authors declare no competing financial interests.

Reprints and permission information is available online at http://npg.nature.com/ reprintsandpermissions/

How to cite this article: Zhu, S. and Gao, B. Nematode-derived drosomycin-type antifungal peptides provide evidence for plant-to-ecdysozoan horizontal transfer of a disease resistance gene. Nat. Commun. 5:3154 doi: 10.1038/ncomms4154 (2014). 